\title{
S2-2014 Project: a tour
}

\author{
Laura Peruzza ${ }^{1}$ Francesca Pacor $^{2}$ (D)
}

Received: 3 March 2017/Accepted: 12 March 2017/Published online: 6 April 2017

(C) Springer Science+Business Media Dordrecht 2017

\begin{abstract}
This Special Issue describes some steps for introducing measurable improvements into Probabilistic Seismic Hazard Assessment, done during the Italian Project S22014 "Constraining Observations into Seismic Hazard". The papers here gathered cover different topics, but are joint by the common aim of confronting models' results with observations. In this volume, some contributions for improving the quality and quantity of data archives, the design of new tools for seismic hazard assessment, the development of innovative methodological approaches for sanitizing data incompleteness, and a few case studies for ranking and scoring the seismic hazard results are presented. We dedicate this volume to the friend and colleague Marco Mucciarelli that passed away in November 2016: we keep in our heart the energy and humor he put into the several research branches and activities he promoted inside this project.
\end{abstract}

Keywords Seismic hazard · Observations · Site effects · Hazard validation

\section{Foreword}

Project S2-2014 "Constraining Observations into Seismic Hazard" was carried out during the second and last year of six projects funded in Italy in the frame of the 2012-2021 Agreement between the National Civil Defence Department (DPC) and the National Institute of Geophysics and Volcanology (INGV); the Section C of this program concerns cooperative efforts of several universities and institutions, for defining original researches in Applied Seismology and Volcanology.

Francesca Pacor

francesca.pacor@ingv.it

1 Istituto Nazionale di Oceanografia e di Geofisica Sperimentale, Borgo Grotta Gigante 42/C, 34010 Sgonico, TS, Italy

2 Istituto Nazionale di Geofisica e Vulcanologia, Via Alfonso Corti 12, 20133 Milan, Italy 
S2 2012-14 concerns the mid-long term Seismic Hazard Assessment (SHA) in Italy, with an initial setup of two priority areas, the Po Plain in northern Italy, struck by the 2012 Emilia seismic sequence and peninsular southern Italy, characterized by elevated seismic hazard. Intermediate reports, presentations, datasets and partial results of the project have been conceived as public resources for the whole scientific community and are still fully available on twin project's websites (for S2-2012 and for S2-2014: https://sites.goo gle.com/site/ingvdpc2012progettos2/ and https://sites.google.com/site/ingvdpc2014proget tos $2 /$, respectively).

The S2-2014 Project has produced deliverables and results in the field of the probabilistic seismic hazard assessment (PSHA) relative to the tuning and application of validation methods, implementation of innovative methodologies to include site effects, exploitation of detailed seismotectonic models, and development and acquisition of new tools and data useful for seismic hazard. This issue describe some of the steps done to introduce measurable improvements to PSHA. Conversely, this volume does not describe the activities the project has promoted in relation to the topics of induced seismicity and seismic risk perception, as these themes does not fit the Journal interests; for their potential implications on seismic hazard reduction strategies, interested readers may refer to the deliverables and materials on websites (e.g. http://www.sismicitaindotta.it/news/s2inworkshopsullasismicitaindotta), or to some papers recently published (e.g. Mucciarelli et al. 2015; Peruzza et al. 2015; Stabile et al. 2015; Crescimbene et al. 2015).

The leading idea of the entire project is to develop and to test quantitative methods to evaluate the results of different PSHA studies by means of the comparison with observed data. Italy is a country with a long history concerning the collection and archiving of instrumental and macroseismic data. For this reason, both this kind of data represent a valuable set of observables that may be exploited for the aim of the project.

"Modern" instrumental observations are available in Italy since the early '70ies; longlasting accelerometric stations belonging in the past to ENEL (state power company till 1992) and now to the Italian Accelerometric Network (RAN) managed by DPC, are priceless resources. The Italian strong motion database ITACA v2.0 (http://itaca.mi.ingv.it) collects and distributes strong accelerometric waveforms recorded in Italy from 1972, including information on earthquakes and recording stations. During the first phase of the S2 project (S2-2012) the analysis of the ITACA database allowed to build a reference dataset composed by 76 stations (Fig. 1a) satisfying the requirements of a sufficiently long time of operation (at least 25 years).

The first scoring test completed during the first annual phase (Albarello et al. 2014) on this dataset highlighted the need of having high quality site characterizations for the accelerometric stations, and a careful check on completeness of recordings. These are the issues addressed by some of the papers of this special volume.

Within the S2-2014 Project, 43 out of 76 selected recording sites have been investigated to provide detailed site-specific characterizations (Fig. 1b). The analyses have regarded: geological survey to derive maps and stratigraphic cross-section at large scale; low-cost geophysical investigations (MASW, ESAC, P-MASW) to obtain the shear-wave velocity profiles and microtremor measurements to estimate the resonance frequency of the site. All these data have been used to improve the estimate of the soil response to earthquakes and to correctly assign the EC8 soil-category at these stations. Notably, about 1/2 of the studied stations had changed their previously soil category, inferred only on the basis of surface geology. All the newly collected data have been included in the ITACA database, increasing of about $50 \%$ the number of stations for which good geological and geophysical information is available. The paper by Felicetta et al. (2016) briefly presents the update of 

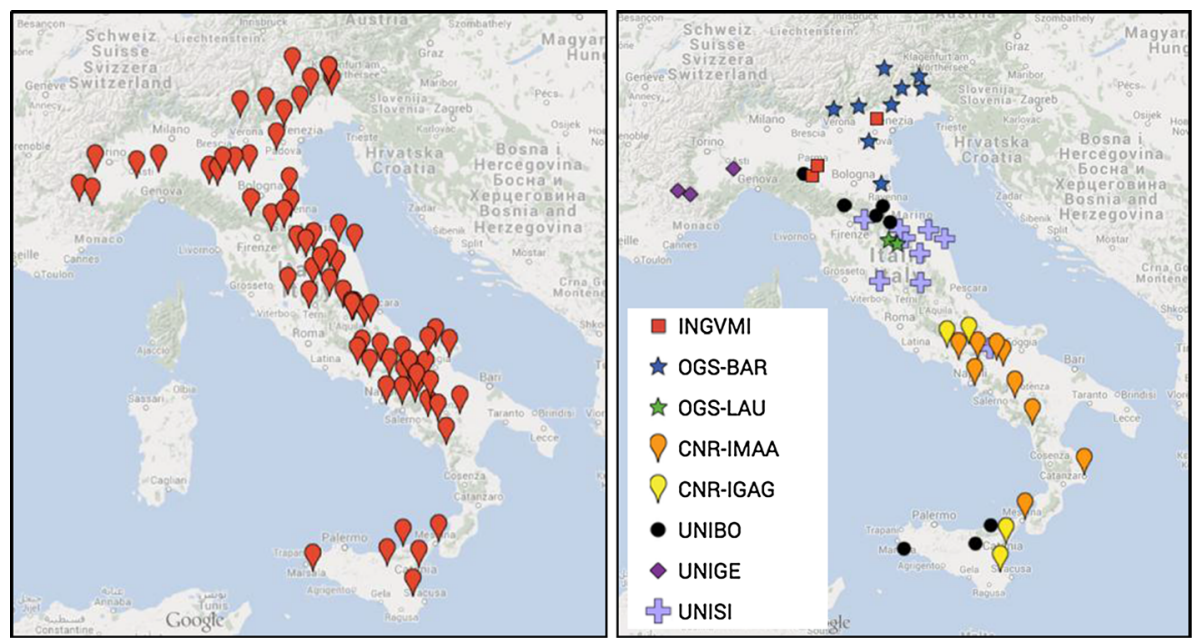

Fig. 1 Accelerometric stations selected for the S2-2014 Project analyses: a long-lasting RAN (Rete Accelerometrica Nazionale, http://www.protezionecivile.gov.it/jcms/it/ran.wp) sites with more than 25 years of recordings; b stations that underwent to specific site characterization by Project participants (Research Units marked by different symbols) during the project S2-2014

the ITACA database that contains recordings and site information for existing and dismantled stations. All the data gathered up to now have been checked and eventually revised using the information collected during this project, thus improving the quantity and quality of the Italian strong motion dataset.

The papers of Massa et al. (2016) and Mucciarelli et al. (2017) describe ambient vibration measurements used to derive resonance frequency and shear-wave velocity profile at some stations in northern and southern Italy, respectively. The papers also discuss the limits of these techniques when applied in complex geomorphological contexts, such as very deep sedimentary sites in the Po plain or sites where the 1D soil profile cannot be assumed.

The results of the soil response analyses for validating the soil classification at the accelerometric stations are exploited in two other papers. In these cases, data relative to the site characterization are used to de-convolve the accelerometric observations recorded on surface and to retrieve the ground motions at outcropping bedrock. This step is fundamental for taking correctly into account the site effects and for providing a qualified dataset for ranking and scoring the PSHA results on rock sites. Castellaro and Albarello (2016) describe the deconvolution procedure that accounts for the uncertainties in the input parameters and includes some randomization of the shear-wave profile, of the damping and shear modulus variation with strain curves and of the depth of the seismic bedrock. In general, surface/outcropping bedrock ratios rarely exceed a factor 2 irrespective to the ground motion parameter of concern. Notably, the deconvolution coefficients are higher than the ones assigned by the Italian seismic code (Norme tecniche delle Costruzioni, NTC 2008) and this fact has some consequences on validation testing and scoring.

Laurenzano et al. (2016) present the case study of the Mirandola accelerometric station (northern Italy). The authors address the issue of evaluating the seismic site response for sites located on large alluvial plains, for which no reference sites can be identified, but some earthquakes can be simultaneously recorded at both surface and depth. In the 
proposed method, surface and borehole records are firstly used to assess the local 1D velocity model, then a model representing a virtual reference rock site is defined, and finally the spectral amplification is calculated through numerical modelling.

Lanzano et al. (2016) update the results of Luzi et al. (2014) on the single-station sigma for Italian strong-motion stations, carried out by means of the residuals analysis. The adopted dataset contains about five times the stations considered in the previous work and updated site categories for the stations, which operated for at least 25 years. For each station, the event-corrected single-station standard deviation and the site-term have been provided. The results of this study can be used as input for the site-specific probabilistic seismic hazard assessment in Italy, removing the ergodic assumption.

In the S2-2014 Project, the applications on macroseismic intensity datasets have been proposed in order to extend the seismic history of recording sites beyond the limited in time availability of strong-motion parameters.

Locati et al. (2016) present an innovative web-tool, Rosetta, aimed at linking intensity data points and strong motion data for a set of localities (the about 70 stations previously mentioned), using interactive and innovative integration of 3D terrain representation. Preliminary relationships between ground motion and macroseismic intensity are also derived for the Italian territory.

The data completeness and the representativeness of the operating time of the stations, as reported in the ITACA database, are crucial issues for PSHA scoring. Fiorini and Bazzurro (2016) suggest how to check the completeness of site seismic histories. They propose to model spatially correlated random fields of peak ground acceleration, constrained by the available instrumental observations and by macroseismic data points to establish if accelerometric recordings at selected sites can be missing or larger than a given threshold.

Grimaz and Malisan (2016) propose a methodology to evaluate the impact on macroseismic intensity assessment due to repeated shakings during long seismic sequences; taking into account the increase of vulnerability on masonry building stocks, they attempt to evaluate the possible effects of the cumulative damages on intensity values assigned to a locality. Their analysis can have important feedback on the parametrisation of past events, thus on the catalogues of historical earthquakes.

The core of the S2 2012-14 Project was the comparison of seismic hazard models with observations; thus, a collection of PSHA results was the starting point of the activities done during the very first year of the project (Faccioli and Vanini 2013). After this gathering of some results available for Italy, the concept of repository has been expanded for including some SHA analyses, i.e. deterministic earthquake simulations of some major recent Italian earthquakes.

The description of SYNTHESIS database by D'Amico et al. (2016) includes the main feature of the web-portal to interactively retrieve simulated waveforms, modelling parameters and information on simulation sites. The bulk of data relates to peer reviewed earthquake simulation studies for Italy; a uniform post-processing procedure is applied in order to guarantee the direct applicability of these synthetic accelerograms for engineering applications.

A new PSHA for southern Italy is provided to the project by Akinci et al. (2016). They acquired new data and tested alternative approaches with respect to the standard model (Gruppo di Lavoro MPS 2004) for the Calabria region; the innovative seismotectonic model combines background seismicity with fault sources, and it allows assigning earthquake probabilities for the large events under Poisson and time-dependent assumptions. 
Clustered and de-clustered catalogues have been also tested, showing their impact on ground motion estimates.

Two papers by Barani et al. (2016) and Barani and Spallarossa (2016) explore methods to introduce the local seismic response in PSHA, and to score Ground Motion Prediction Equations (GMPE) in site specific hazard analyses. A comparison of different probabilistic methods for including site effects into ground motion hazard assessments is presented for three test sites in Italy that are characterized by different geological conditions and seismicity levels. From the simplest method based on customized GMPE, to the most complex procedures that convolve site-specific amplification functions (and their variability) with the hazard curves for reference rock, the authors compare the strengths and weaknesses of the different approaches.

In the second study, they apply an empirical scoring method to evaluate the advantages of PSHAs at a regional scale in Italy using GMPEs for pre-defined soil categories. The procedure is applied to quantify the likelihood of the outcomes of different hazard models, with respect to the observations at 56 accelerometric sites operating in Italy for at least 25 years. The results indicate that although the hazard assessment based on GMPE only is a rough and broad simplification of specific site response, large-scale site-specific hazard maps of Italy are compatible with observations, provided that appropriate GMPEs are used. Only two GMPEs was found adequate to this scope, on seven selected GMPEs derived for active shallow crustal regions like Italy.

Closing the loop of the "Constraining observations into seismic hazard", Albarello and Peruzza (2016) propose a procedure to score probabilistic seismic hazard estimates provided by ergodic models by a comparison with accelerometric observations available at 76 sites continuously operating for more than 25 years. The method accounts for the potential bias induced by spatial correlation of hazard estimates due to the use of ground motion prediction equations in the modelling. Results show that at least in this case study, the amount of spatial correlation in the hazard estimates is relatively weak, GMPE- dependent, and both related to the exceedance probability and to the spectral acceleration.

The editors believe that this volume addresses important questions regarding the validation of seismic hazard studies, exploiting the potentiality of observed data that will in future be even more. The papers presented herein do not provide final results but rather indicate several possible courses of action in the research field of hazard analysis that we hope can be useful for the entire community.

We dedicate this volume to our esteemed and beloved friend and colleague Marco Mucciarelli who passed away on November the 7th, 2016. He promoted several activities inside this project, working, among others, on extensive accelerometric stations characterization, networking on surface-borehole seismological measurements, and leading initiatives on induced and triggered seismicity. This topic was the subject of the very last meeting of S2-2014 project, a Workshop on induced seismicity held in Rome on June 12, 2015 (videos available on http://crs1-depot.ogs.trieste.it/S2in/Eventi/Workshop_2015.06. 12_Roma/).

Acknowledgements The Projects S2-2012 and S2-2014 have benefited of funding, provided by the Italian Presidenza del Consiglio dei Ministri-Dipartimento della Protezione Civile (DPC). The papers included in this special volume do not necessarily represent DPC official opinions and policies. We are very grateful to Agostino Goretti, that supported us and encouraged during the coordination of the S2-2014 Project. 


\section{References}

Akinci A, Vannoli P, Falcone G, Taroni M, Tiberti MM, Murru M, Burrato P, Mariucci MT (2016) When time and faults matter: towards a time-dependent probabilistic SHA in Calabria. Bull Earthq Eng, Italy. doi:10.1007/s10518-016-0065-7

Albarello D, Peruzza L (2016) Accounting for spatial correlation in the empirical scoring of probabilistic seismic hazard estimates. Bull Earthq Eng. doi:10.1007/s10518-016-9961-0

Albarello D, Peruzza L, D’Amico V (2014) A scoring test on probabilistic seismic hazard estimates in Italy. Nat. Hazards Earth Syst Sci Discuss 2:5721-5757. doi:10.5194/nhessd-14-1-2014

Barani S, Spallarossa D (2016) Soil amplification in probabilistic ground motion hazard analysis. Bull Earthq Eng. doi:10.1007/s10518-016-9971-y

Barani S, Albarello D, Spallarossa D, Massa M (2016) Empirical scoring of ground motion prediction equations for probabilistic seismic hazard analysis in Italy including site effects. Bull Earthq Eng. doi:10.1007/s10518-016-0040-3

Castellaro S, Albarello D (2016) Reconstructing seismic ground motion at reference site conditions: the case of accelerometric records of the Italian National Accelerometric Network (RAN). Bull Earthq Eng. doi:10.1007/s10518-016-0032-3

Crescimbene M, La Longa F, Camassi R, Pino NA (2015) The seismic risk perception questionnaire. Geol Soc Lond Spec Publ 419(1):69-77

D’Amico M, Puglia R, Russo E, Maini C, Pacor F, Luzi L (2016) SYNTHESIS: a web repository of synthetic waveforms. Bull Earthquake Eng. doi:10.1007/s10518-016-9982-8

Faccioli E, Vanini E (2013) D1.1 PSHA repository. (Technical report and Annexes] https://sites.google. com/site/ingvdpc2012progettos2/deliverables. Accessed May 2016

Felicetta C, D’Amico M, Lanzano G, Puglia R, Russo E, Luzi L (2016) Site characterization of Italian accelerometric stations. Bull Earthq Eng. doi:10.1007/s10518-016-9942-3

Fiorini E, Bazzurro P (2016) Testing strong motion stations continuity of operation using random fields and intensity data. Bull Earthq Eng. doi:10.1007/s10518-016-9978-4

Grimaz S, Malisan P (2016) How could cumulative damage affect the macroseismic assessment? Bull Earthq Eng. doi:10.1007/s10518-016-0016-3

Gruppo di Lavoro MPS (2004) Redazione della mappa di pericolosità sismica prevista dall'Ordinanza PCM 3274 del 20 marzo 2003, Rapporto conclusivo per il dipartimento di Protezione Civile, INGV, Milano-Roma, 5 appendici. http://zonesismiche.mi.ingv.it/elaborazioni/ (in Italian)

Lanzano G, D’Amico M, Felicetta C, Luzi L, Puglia R (2016) Update of the single-station sigma analysis for the Italian strong-motion stations. Bull Earthq Eng. doi:10.1007/s10518-016-9972-X

Laurenzano G, Priolo E, Mucciarelli M, Martelli L, Romanelli M (2016) Site response estimation at Mirandola by virtual reference station. Bull Earthq Eng. doi:10.1007/s10518-016-0037-y

Locati M, Gomez Capera AA, Puglia R, Santulin M (2016) How could cumulative damage affect the macroseismic assessment? Bull Earthq Eng. doi:10.1007/s10518-016-9955-y

Luzi L, Bindi D, Puglia R, Pacor F, Oth A (2014) Single-station sigma for Italian strong-motion stations. Bull Seismol Soc Am 104:467-483

Massa M, Mascandola C, Ladina C, Lovati S, Barani S (2016) Fieldwork on local-site seismic response in the Po Plain: examples from ambient vibration array and single station analyses. Bull Earthq Eng. doi:10.1007/s10518-016-0017-2

Mucciarelli M, Priolo E, Santulin M, Tamaro A (2015) Seismic hazard from natural and induced seismicity: a comparison for Italy. Bull Geofis Teor Appl 56(4):519-526

Mucciarelli M, Gallipoli MR, Lizza C, Vignola L (2017) Site condition at accelerometric stations in Southern Italy: observations gained from peculiar cases. Bull Earthquake Eng. doi:10.1007/s10518017-0133-7

NTC (2008) Norme tecniche per le costruzioni, Ministero delle Infrastrutture e dei Trasporti, Decreto Ministeriale del 14 gennaio 2008, Supplemento ordinario alla G.U. n. 29 del 4 febbraio 2008

Peruzza L, Garbin M, Snidarcig A, Sugan M, Urban S, Renner G, Romano MA (2015) Quarry blasts, underwater explosions and other dubious seismic events in NE Italy from 1977 till 2013. Bull Geofis Teor Appl 56(4):437-459

Stabile TA, Giocoli A, Perrone A, Piscitelli S, Telesca L, Lapenna V (2015) Relationship between seismicity and water level of the Pertusillo reservoir (Southern Italy). Bull Geofis Teor Appl 56(4):505-517 